\title{
ERRATUM
}

\section{Executive Function in Patients with Obstructive Sleep Apnea Treated with Continuous Positive Airway Pressure-Erratum}

Esther Yuet Ying Lau, Gail A. Eskes, Debra L. Morrison, Malgorzata Rajda, AND Kathleen F. Spurr

doi:10.1017/S1355617710000901, Published online by Cambridge University Press on 25 August, 2010.

The paper by Lau et al. (2010) has errors in the article that should be brought to the attention of readers. The instances are listed with their page numbers along with the incorrect and correct copy:

Page 1082, Table 3, two of the column heads, Pre- and Post-CPAP, are switched (see highlighted copy)

Incorrect copy:

Table 3. Pre- and Post-Treatment Comparisons of Hypoxemia Indices, Sleepiness, and Subjective Sleep Quality

$\begin{array}{llll}\text { OSA Group } & \text { OSA Group } & \text { Controls } & \underline{\text { A vs. B }} \\ \underline{\text { Post-CPAP }} & \underline{\text { Pre-CPAP }} & \underline{B} & \underline{B \text { vs. C }}\end{array}$

Correct copy

Table 3. Pre- and Post-Treatment Comparisons of Hypoxemia Indices, Sleepiness, and Subjective Sleep Quality

\section{OSA Group \\ $\underline{\text { Pre-CPAP }}$}

OSA Group
Post-CPAP

Post-CPAP $\quad$ Controls $\underline{\text { A vs. B }}$

$\underline{B \text { vs. } \mathrm{C}}$

Cambridge University Press and the Editor regret the inconvenience that these errors may have caused. 